Supporting Information to the following manuscript:

\title{
Oxidation kinetics of selected taste and odour compounds during ozonation of drinking water
}

\author{
ANDREAS PETER AND URS VON GUNTEN \\ Eawag, Swiss Federal Institute of Aquatic Science and Technology, \\ Ueberlandstrasse 133, CH-8600 Duebendorf, Switzerland
}

journal: Environmental Science and Technology

date: September 12, 2006

number of pages: 1

number of tables: 2 
S1, table1. Overview of analytical methods based on HPLC.

\begin{tabular}{|c|c|c|c|c|c|c|}
\hline compound & detection & $\begin{array}{l}\text { detection wavelength } \\
\mathrm{nm}\end{array}$ & $\begin{array}{l}\text { retention } \\
\min \end{array}$ & isocratic conditions & $\begin{array}{l}\text { linearity } \\
\qquad \mu \mathrm{M}\end{array}$ & $\begin{array}{c}\text { detection limit } \\
\mu \mathrm{M}\end{array}$ \\
\hline$\beta$-cyclocitral & UV & 253 & 5.1 & $70 \% \mathrm{MeOH} / 30 \% \mathrm{H}_{2} \mathrm{O}$ & $0.3-50$ & $<0.1$ \\
\hline geosmin & MS/MS & - & 12.3 & $80 \% \mathrm{MeOH} / 20 \% \mathrm{H}_{2} \mathrm{O}$ & $1-25$ & $<1$ \\
\hline cis-3-hexen-1-ol & UV & 200 & 4.6 & $50 \% \mathrm{MeOH} / 50 \% \mathrm{H}_{2} \mathrm{O}$ & $0.3-50$ & 0.1 \\
\hline$\beta$-ionone & UV & 303 & 4 & $80 \% \mathrm{MeOH} / 20 \% \mathrm{H}_{2} \mathrm{O}$ & $0.3-50$ & $<0.1$ \\
\hline $\begin{array}{l}\text { 2-isopropyl-3- } \\
\text { methoxypyrazine }\end{array}$ & UV & 291 & 6.5 & $\begin{array}{c}60 \% \mathrm{MeOH} / 40 \% \text { phosphate } \\
\text { buffer }(\mathrm{pH} 2)\end{array}$ & $0.3-50$ & $<0.1$ \\
\hline 2-methylisoborneol & $\mathrm{MS} / \mathrm{MS}$ & - & 8.7 & $80 \% \mathrm{MeOH} / 20 \% \mathrm{H}_{2} \mathrm{O}$ & $0.3-25$ & 0.005 \\
\hline trans,cis-2,6-nonadienal & UV & 224 & 5.8 & $65 \% \mathrm{MeOH} / 35 \% \mathrm{H}_{2} \mathrm{O}$ & $0.3-50$ & $<0.1$ \\
\hline 1-penten-3-one & UV & 211 & 3.4 & $40 \% \mathrm{MeOH} / 60 \% \mathrm{H}_{2} \mathrm{O}$ & $0.3-50$ & $<0.1$ \\
\hline $\begin{array}{l}\text { 2,6-di-tert-butyl-4- } \\
\text { methylphenol (BHT) }\end{array}$ & UV & 223 & 8.1 & $80 \% \mathrm{MeOH} / 20 \% \mathrm{H}_{2} \mathrm{O}$ & $0.3-4$ & 0.1 \\
\hline 2,4,6-tribromoanisole & UV & 209 & 7.4 & $80 \% \mathrm{MeOH} / 20 \% \mathrm{H}_{2} \mathrm{O}$ & $0.3-5$ & 0.1 \\
\hline 2,4,6-trichloroanisole & UV & 223 & 5.6 & $80 \% \mathrm{MeOH} / 20 \% \mathrm{H} 2 \mathrm{O}$ & $0.3-20$ & 0.1 \\
\hline
\end{tabular}

S1, table 2. Mass spectrometry conditions for the HPLC analysis of geosmin and 2-methylisoborneol (MIB)

\begin{tabular}{|llcc|}
\hline & & geosmin & MIB \\
ionisation mode & & APcl+ & APcl+ \\
voltage $(\mathrm{V})$ & capillary & 3.5 & 12 \\
& tube lens & 32 & 41 \\
temperature $\left({ }^{\circ} \mathrm{C}\right)$ & vaporizer & 480 & 480 \\
& capillary & 180 & 180 \\
Gas & sheath gas & 30 & 30 \\
& aux gas & 5 & 5 \\
Current $(\mu \mathrm{A})$ & sweep gas & 0 & 0 \\
& discharge & 5 & 5 \\
precursor ions & & & \\
product ions (MS/MS) & & 165.1 & 151.2 \\
(fat $=$ used for quantitative analysis) & $\mathbf{1 0 9 . 0}$ & $\mathbf{9 5 . 0}$ \\
\hline
\end{tabular}

